\title{
The thn mutation of Schizophyllum commune, which suppresses formation of aerial hyphae, affects expression of the $S c 3$ hydrophobin gene
}

\author{
J. G. H. Wessels, ${ }^{*}$ O. M. H. De VRies, S. A. ÁsgeirsdótTir and J. Springer \\ Department of Plant Biology, Biological Center, University of Groningen, Kerklaan 30, 9751 NN Haren, The Netherlands
}

(Received 15 March 1991; revised 24 June 1991; accepted 28 June 1991)

\begin{abstract}
The spontaneous and recessive mutation thn in the basidiomycete Schizophyllum commune suppresses the formation of aerial hyphae in the monokaryon and, if present as a double dose, the formation of both aerial hyphae and fruit-bodies in the dikaryon. In the monokaryon, the mutation prevents accumulation of mRNA of the Sc3 gene, and in the dikaryon it also prevents the accumulation of fruiting-specific mRNAs, including mRNAs of the $S c 1$ and $S c 4$ genes, which are homologous to the $S c 3$ gene. These three genes code for hydrophobins, a family of small hydrophobic cysteine-rich proteins. In the thn monokaryon, the only detectable change in synthesized proteins is the disappearance of an abundant protein of apparent $M_{\mathrm{r}}=28 \mathrm{~K}$ from the culture medium and from the cell walls. Protein sequencing shows that this is the product of the $S c 3$ gene. The $\mathrm{Sc} 3$ hydrophobin is present in the walls of aerial hyphae as a hot-SDS-insoluble complex. Submerged hyphae excrete large amounts of the hydrophobin into the medium.
\end{abstract}

\section{Introduction}

The Sc3 gene of the basidiomycete Schizophyllum commune codes for a protein of 125 amino acids $\left(M_{\mathrm{r}}=\right.$ 12386) which shares sequence homology with similarly sized products of two other genes, $S c 1$ and $S c 4$ (Schuren $\&$ Wessels, 1990). These proteins, which collectively we call hydrophobins because of their high content of hydrophobic amino acids, each have 8 cysteines conserved at identical positions and contain putative signal sequences for secretion. However, unlike the $S c 1$ and $S c 4$ genes, which are only expressed in dikaryons at the time of fruiting, the mRNA of the $S c 3$ gene accumulates at high concentrations in both monokaryons and dikaryons at the time of formation of aerial hyphae (Mulder \& Wessels, 1986). Whereas the mRNAs of the $S c 1$ and $S c 4$ genes also accumulate in developing fruit-bodies, the mRNA of the $S c 3$ gene is more restricted to the vegetative mycelium (Mulder \& Wessels, 1986; Ruiters $\&$ Wessels, 1989). However, the expression of the $S c 3$ gene is variable and we have noticed lower expression where surface cultures failed to produce abundant aerial mycelium, such as in young cultures grown as a lawn from a mycelial homogenate, during heavy fruiting of similarly grown dikaryons, and in occasionally arising genetic variants of the monokaryons with a strongly reduced ability to form aerial hyphae. Such variants have earlier been described in $S$. commune (Schwalb \& Miles,
1967) and were shown to be due to a frequently occurring spontaneous mutation, called thin (thn) (Raper \& Miles, 1958). Here we report that the $T H N$ gene is required for the expression of the $S c 3$ gene and for the expression of all known fruiting-specific genes in the dikaryon. In the monokaryon, the thn mutation leads to disappearance of the $\mathrm{Sc} 3$ hydrophobin which is normally excreted into the culture medium and present as a hot-SDS-insoluble complex in the walls of aerial hyphae.

\section{Methods}

Strains, culture conditions, and labelling. The co-isogenic strains 4-39 (A41 B41, CBS 341.81 ) and 4-40 (A43 B43, CBS 340.81) of S. commune, the co-isogenic thin mutants (thn), and derived dikaryons were grown from a mycelial homogenate as a lawn on the surface of minimal medium (Dons et al., 1979) in continuous light at $24^{\circ} \mathrm{C}$ for $4 \mathrm{~d}$. For RNA isolations, the mycelia were grown directly on medium solidified with $0.7 \%$ agar. For labelling experiments, mycelia were mostly grown for $3 \mathrm{~d}$ on water-permeable cellophane (330P, British Cellophane Ltd, Bridgewater, UK) overlaying $0.7 \%$ agar medium. The mycelia growing on the cellophane membrane (diameter $4.8 \mathrm{~cm}$ ) were then detached and floated onto $4 \mathrm{ml}$ liquid minimal medium containing $9.25 \mathrm{MBq} \mathrm{ml}^{-1}$ $\left[{ }^{35}\right.$ S] sulphate (specific activity $1000-1500 \mathrm{GBq} \mathrm{mg}^{-1} ; \mathrm{MgCl}_{2}$ replacing $\mathrm{MgSO}_{4}$ in the medium) and cultivation continued for $24 \mathrm{~h}$. Alternatively, labelling was done with $400 \mathrm{kBq} \mathrm{m}^{-1}\left[{ }^{14} \mathrm{C}\right]$ leucine (specific activity $>11 \mathrm{GBq} \mathrm{mmol}^{-1}$ ) or $400 \mathrm{kBq} \mathrm{ml}^{-1}\left[{ }^{14} \mathrm{C}\right] \mathrm{lysine}$ (specific activity $>11 \mathrm{GBq} \mathrm{mmol}^{-1}$ ). To isolate submerged and aerial hyphae separately, the mycelium was grown on a nylon net $(50 \mu \mathrm{m}$ mesh) floating on liquid medium (Mulder \& Wessels, 1986). Hyphae 
protruding from the underside of the net were scraped off (submerged hyphae) and the remainder peeled off the net (aerial hyphae contaminated with submerged hyphae). Alternatively, the mycelium was grown on a perforated polycarbonate membrane (standard pore size $0.08 \mu \mathrm{m}$, Nuclepore) overlaying agar medium. After inoculation with a mycelial homogenate, a nylon net $(50 \mu \mathrm{m}$ mesh) was placed on top of the culture so that aerial hyphae could grow through the net. Scraping the surface of the net permitted isolation of a pure sample of aerial hyphae, the remainder containing submerged hyphae contaminated with some aerial hyphae. Placing a perforated polycarbonate membrane on top of the inoculum, instead of a nylon net, prevented formation of any aerial hyphae and permitted isolation of submerged mycelium only. All these cultures were labelled $\left(277 \mathrm{kBq} \mathrm{ml}^{-1}\right.$ ${ }^{35}$ S]sulphate in medium with $0.5 \mathrm{mg} \mathrm{ml}^{-1} \mathrm{MgSO}_{4}$ ) during the whole period of growth. The isolated hyphal material was frozen in liquid nitrogen and stored at $-70^{\circ} \mathrm{C}$.

Quantification of mRNAs. Total RNA was isolated, denatured, spotted onto Genescreen-plus membrane, and hybridized to ${ }^{32} \mathrm{P}$ labelled cDNA clones (Mulder \& Wessels, 1986; Ruiters et al., 1988). Radioactivity was measured by liquid-scintillation counting. Hybridization to a clone of the gene for $18 \mathrm{~S}$ rRNA served to compare the amounts of total RNA spotted.

SDS-soluble proteins. To the culture medium used in brief labelling experiments, 1 vol. of the culture medium from a 4-d-old dikaryon was added for co-precipitation. The medium was then made up to $5 \%(\mathrm{w} / \mathrm{v})$ in TCA, and precipitated proteins were collected after $1 \mathrm{~h}$ on ice. The precipitate was washed twice with $5 \%(\mathrm{v} / \mathrm{v})$ TCA containing $10 \mathrm{~mm}$ $\mathrm{MgSO}_{4}$ in the case of labelling with $\left.{ }^{35} \mathrm{~S}\right]$ sulphate, and dissolved in SDS sample buffer $[2 \%$ (w/v) SDS, $0.05 \mathrm{~m}$-Tris $/ \mathrm{HCl}, \mathrm{pH} 6.8,10 \%$ (v/v) glycerol, $0.001 \%$ bromophenol blue] by heating at $100{ }^{\circ} \mathrm{C}$ for $10 \mathrm{~min}$. SDS-soluble mycelial proteins were obtained as follows: the mycelium was fragmented in an X-press (AB Biox, Göteborg, Sweden) at $-25^{\circ} \mathrm{C}$, and the broken material was quickly thawed in extraction buffer $\left(0.1 \mathrm{M}\right.$-Tris/HCl, pH 8.0, $\left.10 \mathrm{~mm}-\mathrm{MgSO}_{4}, 1 \mathrm{~mm}-\mathrm{PMSF}\right)$. To obtain total SDS-soluble proteins, the suspension was immediately brought to $5 \%$ TCA. The precipitate was washed twice with $5 \%$ TCA, $10 \mathrm{mM}-\mathrm{MgSO}_{4}, 1 \mathrm{~mm}$-cysteine, $1 \mathrm{~mm}$-methionine, then twice with cold acetone $\left(-20^{\circ} \mathrm{C}\right)$, and dried. Proteins were extracted with SDS sample buffer at $100^{\circ} \mathrm{C}$ for $10 \mathrm{~min}$. For cell-wall proteins, cell walls were prepared by centrifuging $(1500 \mathrm{~g})$ the broken mycelium in extraction buffer, and washing the pellet three times with extraction buffer and twice with water. The washed walls were freeze-dried and then extracted with SDS sample buffer at $100^{\circ} \mathrm{C}$ for $10 \mathrm{~min}$.

Dissolution of proteins with formic acid and oxidation with performic acid. Walls extracted with SDS, washed twice with water, and freezedried, were subsequently extracted with $98 \%$ formic acid $[100 \mu \mathrm{l}$ $(\mathrm{mg} \text { dry wt) })^{-1}$ ] in a sonicating water bath (Sonicor Instruments, Farmingdale, NY, USA) for $1.5 \mathrm{~h}$, keeping the temperature below $10{ }^{\circ} \mathrm{C}$. After centrifugation, 2 vols performic acid were added to the supernatant, and oxidation was allowed to proceed on ice for $4 \mathrm{~h}$ to cleave disulphide bonds. Performic acid was prepared by mixing 1 vol. $30 \%$ (v/v) $\mathrm{H}_{2} \mathrm{O}_{2}$. with 9 vols $98 \%$ formic acid and was used after standing at room temperature for $1 \mathrm{~h}$. Formic acid extracts, before and after oxidation with performic acid, were diluted 20 times with water, freeze-dried, and dissolved in SDS sample buffer. TCA-precipitated proteins from culture media were also dissolved in formic acid and oxidized with performic acid before being taken up in SDS sample buffer.

$P A G E$ and protein sequenicing. Electrophoresis was generally done in $12.5 \%$ (w/v) polyacirylamide gels according to Laemmli (1970). For autoradiography, gels were soaked in $1 \mathrm{M}$-sodium salicylate immediately after electrophoresis (Chämberlain, 1979), dried at $65^{\circ} \mathrm{C}$, and exposed to pre-flashed film (Kodak Xomat AR). For amino-terminal protein sequencing, electrophoresis was done with the neutral buffer system MZE-3328IV of Jovin (1973) and gels were stored overnight prior to use to avoid amino-terminal blockage during electrophoresis (Moos et al., 1988). Electroblotting was done on PVDF membrane (Immobilon-P, Millipore) by semi-dry transfer (Multiphor II Electrophoresis System, Pharmacia) at $0.8 \mathrm{~mA} \mathrm{~cm}^{-2}$ for $2 \mathrm{~h}$. The blot was stained for $30 \mathrm{~min}$ in a fresh solution of $0.1 \%$ Coomassie Brilliant Blue $\mathrm{R} 250$ in $10 \%(\mathrm{v} / \mathrm{v})$ acetic acid, $30 \%(\mathrm{v} / \mathrm{v})$ methanol and destained in the same solvent for $3 \mathrm{~h}$. Protein bands of interest, which were negatively stained by this procedure, were excised and amino acid sequencing was carried out with a pulse liquid sequenator on line connected to a PTH analyser (Applied Biosystems, Foster City, CA, USA).

\section{Results}

\section{Genetics and morphology of the thn mutants}

Over the years we have regularly encountered thin variants with few aerial hyphae, wavy submerged hyphae, and a pungent smell in the strains 4-39 (A41B4I) and 4-40 (A43B43) of $S$. commune. Mostly the whole colony turned thin; rarely, a thin sector appeared in an otherwise normal-looking colony. For the purpose of the present investigation we isolated a few of these variants, both from strains 4-39 and 4-40. In crosses with the compatible wild-type strains bilateral dikaryotization occurred, though somewhat more slowly on the thin side, with the formation of aerial mycelium and fruit-bodies at both sides. In the monokaryotic progeny, a $1: 1$ segregation of the thin phenotype occurred, showing that thin behaves as a recessive Mendelian mutation (thn). In crosses between compatible independently isolated $t h n$ mutants, dikaryons always displayed the thin morphology and produced few fruit-bodies at the edge of the Petri dish only, or none at all. The thn mutants we isolated (about 10) thus all appear allelic, suggesting that the $T H N$ gene is a highly mutable locus. The mutation matches the phenotype described in detail by Schwalb \& Miles (1967) in every respect, and probably corresponds to $t h n-1$, mapped on linkage group II (Raper, 1988 and personal communication) but we did not perform a linkage analysis to confirm this. We did however establish that $t h n$ is not allelic to $f b f$, another frequently occurring recessive mutation which blocks fruiting, but not the formation of aerial hyphae (Springer \& Wessels, 1989). In a thn $\times f b f$ cross, normal formation of aerial hyphae and fruit-bodies occurred on both sides of the mating.

When grown as colonies from a single inoculum, the thn monokaryons had a faster linear growth rate than their wild-type progenitors, had a more regular colony margin, and produced few aerial hyphae. With respect to the formation of aerial structures, the phenotypic expression of thn in monokaryons and dikaryons was best seen when mycelia were grown as a lawn from a 

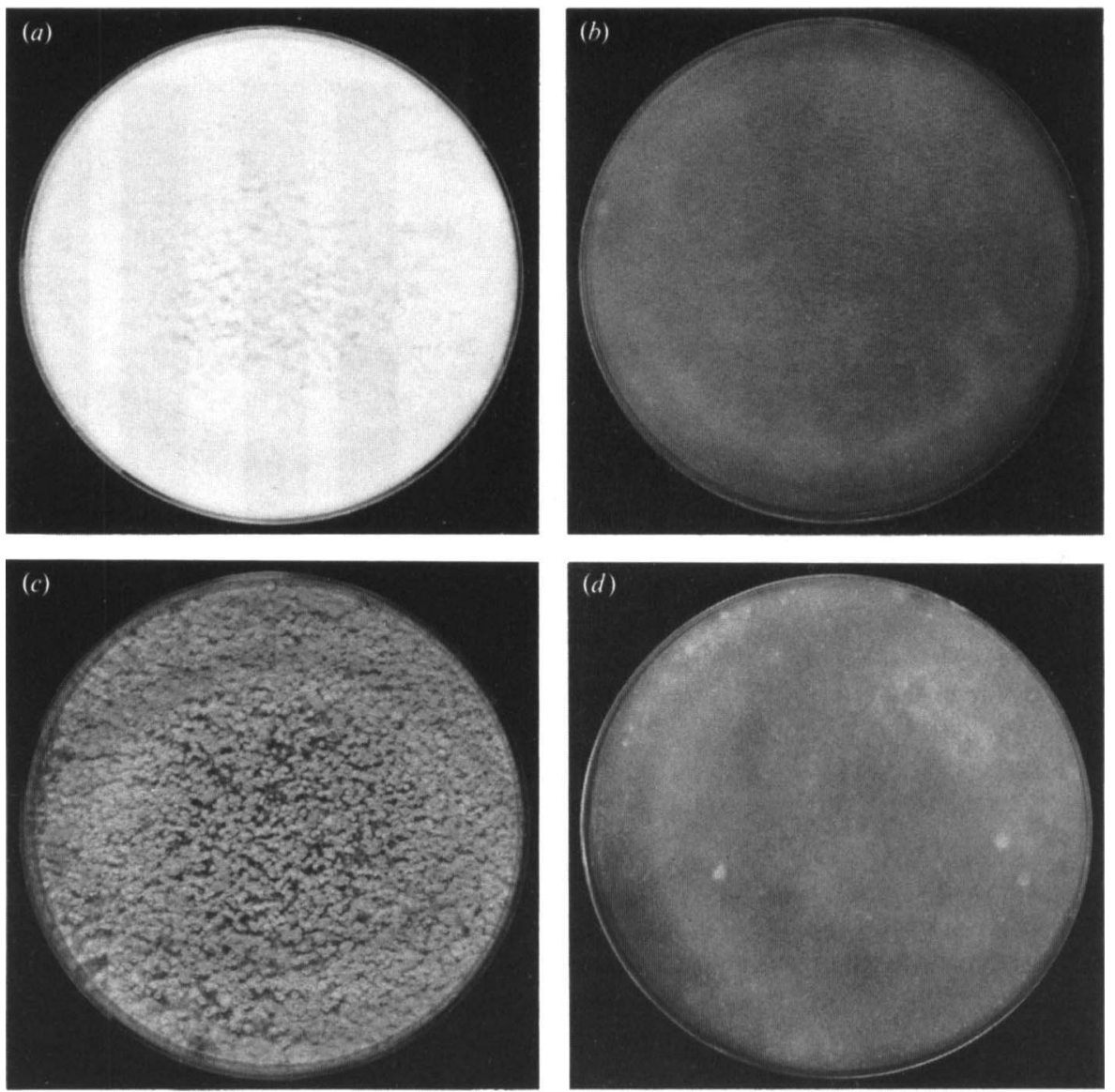

Fig. 1. Four-day-old cultures of $S$. commune without $(a, c)$ and with $(b, d)$ the thn mutation, grown as lawns from mycelial homogenates on minimal agar medium. (a) A4I B4I (4-39); (b) A4I B4I thn (4-39-1); (c) A41 B4I $\times A 43$ B43; and (d) A4I B4I thn $\times A 43$ B43 thn.

mycelial homogenate spread over the surface of an agar medium (Fig. 1). The analyses detailed below were made from such cultures. It is important to note that the mutation had no effect on synthetic capacities in general; the dry weights of the mycelia shown in Fig. 1 were approximately the same, and all incorporated $\left[{ }^{35} \mathrm{~S}\right]$ from sulphate into protein at about the same rate.

\section{Expression of Sc genes}

Cultures as shown in Fig. 1 were harvested and analysed for the presence of specific mRNAs by dot-blot analysis (Table 1). As expected from previous studies (Mulder \& Wessels, 1986; Ruiters et al., 1988), hybridizations detected only Sc3 hydrophobin mRNA in wild-type monokaryons, but the derived dikaryon also accumulated fruiting mRNAs, including the $\mathrm{Scl}$ and $\mathrm{Sc} 4$ hydrophobin mRNA. In the presence of the thn mutation, the concentration of Sc3 mRNA in the monokaryons dropped to very low levels, and a double dose of $t h n$ also prevented accumulation of the fruiting mRNAs in the dikaryon. In both wild-type mono-
Table 1. Abundance of specific mRNAs in 4-d-old surface cultures of monokaryons and derived dikaryons in the absence and presence of the thn mutation

Each value represents the mean of two cultures. Maximum variation between mRNA concentrations of duplicate cultures was $5 \%$ of the values indicated.

\begin{tabular}{lccccccc}
\hline \hline & \multicolumn{6}{c}{$10^{3} \times$} & Percentage of total RNA \\
\cline { 2 - 7 } & Sc1 & Sc2 & Sc3 & Sc4 & Sc5 & Sc6 & Sc7 \\
\hline A41B41 & ND & ND & 23.5 & ND & ND & ND & ND \\
A41B41thn & ND & ND & $2 \cdot 8$ & ND & ND & ND & ND \\
A43B43 & $1 \cdot 4$ & ND & $63 \cdot 6$ & ND & ND & ND & ND \\
A43B43thn & ND & ND & ND & ND & ND & ND & ND \\
A41B41 $\times$ A43B43 & 33.0 & 1.5 & $5 \cdot 5$ & 32.5 & $5 \cdot 2$ & $7 \cdot 5$ & $3 \cdot 2$ \\
A41B4Ithn $\times$ A43B43thn & ND & ND & ND & ND & ND & ND & ND \\
\hline \hline
\end{tabular}

ND, Not detected, i.e. an abundance of less than $0.5 \times 10^{-3} \%$.

karyons, the concentration of the Sc3 mRNA was high but somewhat variable (Table 1). This is probably due to the fact that the concentration of this mRNA peaks on about the fourth day of culture (Mulder \& Wessels, 1986), and thus small differences in developmental age between 
(a)

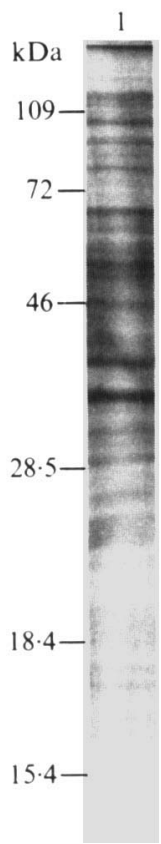

(b)

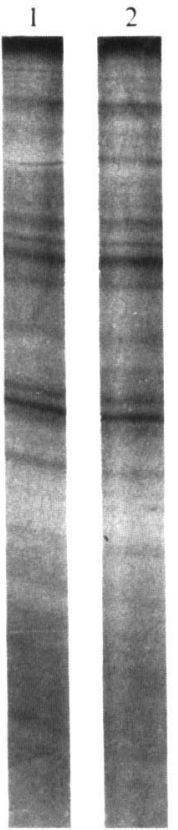

Fig. 2. SDS-PAGE autoradiographs of hot-SDS-extractable ${ }^{35} \mathrm{~S}-$ labelled proteins in extracts obtained from $(a)$ whole mycelium; $(b)$ cell walls. Lanes: 1 , wild-type monokaryon $4-39 ; 2$, the derived thn mutant 4-39-1. Equal amounts of TCA-precipitable radioactive material were loaded on each gel.

cultures can result in large differences in the specific mRNA concentration. Also noteworthy is the low concentration of Sc3 mRNA in the wild-type dikaryon. This correlated with the near complete absence of aerial hyphae in this culture (Fig. 1). The mRNA mass in these cultures has been estimated to amount to $3 \%$ of the total RNA mass (Hoge et al., 1982). A concentration of the Sc 3 mRNA of $0.05 \%$ would thus indicate that this mRNA constitutes $1.5 \%$ of the total mRNA mass. In the wild-type monokaryon the $S c 3$ gene could thus code for a very abundant protein which would be virtually absent in the thn mutant.

\section{Differential synthesis of proteins by a wild-type monokaryon and a coisogenic thn mutant}

The monokaryon (4-39) and a derived thn mutant (4-391) were grown for $4 \mathrm{~d}$ and labelled with $\left[{ }^{35}\right.$ S $]$ sulphate during the last day for harvest (see Methods). We used $\left.{ }^{35} \mathrm{~S}\right]$ label because of the high cysteine content of the putative Sc3 protein but refrained from using $\left[{ }^{35} \mathrm{~S}\right]$ methionine because this amino acid is only present at the amino terminus of the putative signal sequence (Schuren \& Wessels, 1990). Also, this amino acid is not transported into fruit-bodies (de Vries \& Wessels, 1984). However, after labelling with $\left[{ }^{35}\right.$ S $]$ sulphate, hot-SDS (a)

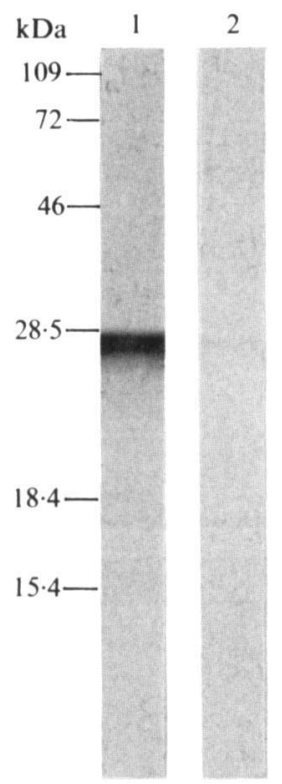

(b)

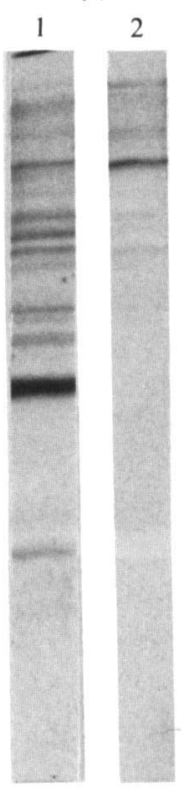

(c)

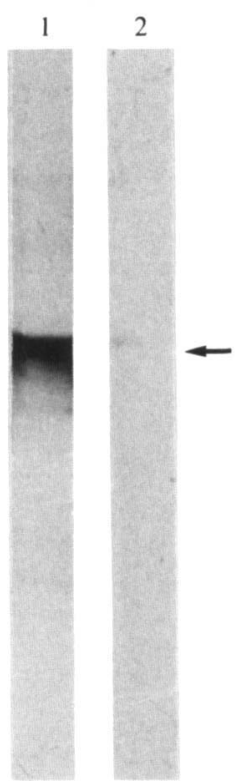

Fig. 3. SDS-PAGE autoradiographs of ${ }^{35} \mathrm{~S}$-labelled proteins in: (a) formic acid extracts from walls previously extracted with hot SDS and oxidized with performic acid before electrophoresis; (b) TCA precipitates from the culture media; $(c)$ as $(b)$ but oxidized with performic acid. Lanes: 1 , wild-type monokaryon $4-39 ; 2$, the derived thn mutant 4-39-1. For comparison, theramounts loaded per lane were obtained from samples of mycelia containing equal amounts of TCAprecipitable radioactive material.

extracts of broken mycelia failed to reveal significant differences between the strains after one-dimensional electrophoresis (Fig. 2a).

Because the amino acid sequence derived from the $\mathrm{Sc} 3$ sequence (and from the $S c I$ and $S c 4$ sequences) indicated the presence of a signal sequence for secretion (Schuren \& Wessels, 1990), we examined the proteins excreted into the cell walls and into the medium during labelling. Whereas the medium of the wild-type monokaryon contained $3.2 \%$ of the counts incorporated into TCAprecipitable material, the washed cell walls of this monokaryon contained about $20 \%$ of the counts. Sixty percent of the labelled material could be removed from these walls by boiling in SDS buffer. When such SDS extracts made from cell walls of wild-type and thin monokaryon were compared by electrophoresis, no significant difference was seen (Fig. 2b). Subsequent cold formic acid extraction removed $80 \%$ of the residual radioactivity from the walls of the wild-type monokaryon. The extracted material was apparently of high molecular mass, because it did not penetrate into the SDS gels. However, after performic acid oxidation, this material resolved into a product (or a few closely spaced products) running at a position of approximately $28 \mathrm{~K}$ (Fig. 3a). As shown, very little of this product could be 
found in the thn mutant. After taking up a TCA precipitate of medium proteins in SDS buffer, the wildtype monokaryon showed an apparently complex pattern of excreted proteins, but very few proteins were excreted into the medium by the thn mutant (Fig. $3 b$ ). However, after treating the TCA precipitate with formic and performic acid, the complex pattern seen in the medium of the wild-type monokaryon resolved into just one band (or a few closely spaced bands) at a position of $28 \mathrm{~K}$ which was not seen in the thn mutant (Fig. $3 c$ ).

\section{The wall-bound $28 \mathrm{~K}$ protein occurs only in aerial hyphae}

If the SDS-insoluble complex of $28 \mathrm{~K}$ subunits is essential for the occurrence of aerial hyphae, one would expect to find it in such hyphae. The wild-type monokaryon (4-39) was therefore grown from a mycelial homogenate on the surface of a nylon net floating on minimal liquid medium. After $4 \mathrm{~d}$ growth, pure sample of submerged hyphae was isolated by scraping the underside of the net. The rest of the mycelium was then harvested and categorized as 'aerial', although it also contained submerged hyphae. To avoid differential labelling of substrate hyphae and aerial hyphae, the former developing before the latter, $\left[{ }^{35} S\right]$ sulphate was present during the whole growth period. Using this separation of hyphal types, $91 \%$ of the TCA-precipitable counts were found in the 'aerial' mycelium, indicating heavy contamination with submerged mycelium. The pure submerged mycelium contained $6 \%$ of the counts while $3 \%$ of the counts were found in the culture medium. To make a comparison between cell walls of the 'aerial' and submerged mycelia, the cell walls used for extraction of aerial hyphae were derived from hyphal material with equal TCA-precipitable counts, in the case of the submerged mycelium including the proteins excreted into the medium. Fig. 4 shows that after SDS extraction, the walls of submerged hyphae contained very little of the $28 \mathrm{~K}$ protein; virtually all of this protein was found in the medium. On the other hand, in the walls of the 'aerial' hyphae the $28 \mathrm{~K}$ protein was present in a hot-SDS-insoluble form. However, this experiment did not exclude the possibility that the submerged hyphae present in the 'aerial' sample also contained the insolubilized $28 \mathrm{~K}$ protein, or contributed to the accumulation of the soluble form in the medium. To resolve this uncertainty, we labelled cultures growing on a perforated polycarbonate membrane and covered with a nylon net (see Methods). Aerial hyphae scraped off the surface of the net contained $34 \%$ of the mycelial protein, and the insoluble complex of $28 \mathrm{~K}$ protein was found in abundance in their walls. On a total protein basis, walls from the remaining part of the culture ('submerged') contained 2.5 times less of this complex. The presence of (a) (b) (c)

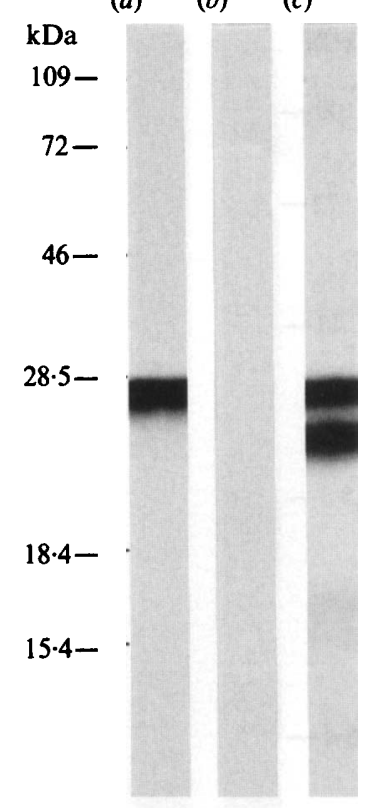

Fig. 4. Presence of the complexed $28 \mathrm{~K}$ protein in the cell walls of aerial hyphae $(a)$ and absence of this protein in cell walls of submerged hyphae $(b)$ but which is excreted into the medium $(c)$. The extracts applied to the gels $a$ and ( $b$ plus $c$ ) were derived from material originally containing equal amounts of TCA-precipitable $\left[{ }^{35} \mathrm{~S}\right]$ counts.

the complex in this fraction could have been due to contamination with aerial hyphae. When a culture was covered with a perforated polycarbonate membrane, instead of a nylon net, no aerial hyphae could develop but submerged growth occurred unimpaired, as indicated by the amount of protein synthesized. On a total protein basis, the walls obtained from such submerged surface cultures contained 25 times less of the $\mathrm{Sc} 3$ hydrophobin complex than the walls of aerial hyphae.

\section{Identity of the $28 \mathrm{~K}$ protein with the product of the $S c 3$ gene}

The correlation between the presence and abundance of the Sc3 mRNA and the $28 \mathrm{~K}$ protein strongly suggests that this protein is the product of the $S c 3$ gene. Aminoterminal sequence analysis showed the sequence [(Gly)Gly-His-Pro-Gly- $\left.X_{a a}-X_{a a}-X_{a a}-P r o-\right]$ as present in the deduced amino acid sequence after 24 amino acids of the signal peptide (Schuren \& Wessels, 1990). The glycine doublet at the amino-terminal end was found in about $40 \%$ of the molecules. Further reading of the sequence was not possible, probably due to the presence of protein modifications. A second band visible (Fig. $4 c$ ) just below the $28 \mathrm{~K}$ band showed the same sequence and thus represents a differently modified form of the $\mathrm{Sc} 3$ protein. The exclusive presence of the $\mathrm{Sc} 3$ hydrophobin at the 


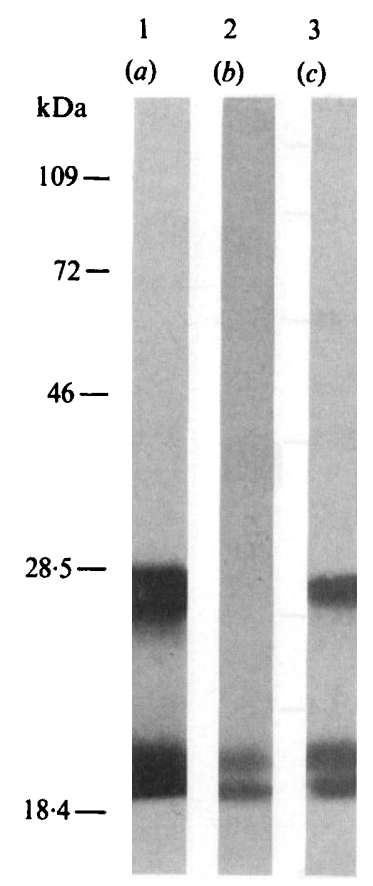

Fig. 5. Differential labelling of the $28 \mathrm{~K}$ protein in the culture medium of the dikaryon 4-39 $\times 4-40$ with $\left[{ }^{35}\right.$ S $]$ sulphate; (2) $\left[{ }^{14} \mathrm{C}\right] l y s i n e ;$ and (3) $\left[{ }^{14} \mathrm{C}\right]$ leucine.

position around $28 \mathrm{~K}$ was further substantiated by showing that a radioactive band at this position could be detected after labelling cultures with $\left[{ }^{35} \mathrm{~S}\right]$ sulphate and $\left[{ }^{14} \mathrm{C}\right]$ leucine, but not with $\left[{ }^{14} \mathrm{C}\right]$ lysine (Fig. 5), the latter amino acid being absent from the deduced sequence of the Sc3 protein (Schuren \& Wessels, 1990). Fig. 5 shows results obtained with medium from the dikaryon to demonstrate the labelling by lysine of products of the $S c 4$ gene (Wessels et al., 1991).

\section{Discussion}

The thin mutation (thn) of $S$. commune has long been recognized, because it arises spontaneously at high frequency in the commonly used monokaryons, and has a distinct phenotype: suppression of the formation of aerial hyphae, the appearance of corkscrew-like or wavy hyphae in the substrate, and the suppression of both aerial hyphae and fruit-bodies in dikaryons when homozygous for thn (Schwalb \& Miles, 1967, Raper, 1988). The nature of this mutation is unknown but because it sometimes appears to occur simultaneously in many nuclei it might involve an epigenetic modification of the gene, e.g. by methylation. However, we have been unable to reverse the phenotype by growing the thin mutant in the presence of 5-azacytidine (data not shown). Here we show that in the monokaryon the $t h n$ mutation prevents accumulation of the mRNA from the $S c 3$ gene, and that in the dikaryon it also prevents the accumulation of the homologous $S c 1$ and $S c 4$ genes and of other fruiting genes. These fruiting genes are under the additional control of the mating-type genes (Mulder \& Wessels, 1986; Ruiters et al., 1988) and the $F B F$ gene (Springer \& Wessels, 1989). The only control element found so far that affects the activity of the $S c 3$ gene is the $T H N$ gene. However, it is important to note that the $S c 3$ gene is also under developmental control. In young cultures the $S c 3$ gene appears to be relatively silent; its mRNA only accumulates at the time of formation of aerial hyphae (Mulder \& Wessels, 1986). When formation of aerial hyphae is prevented, as in shaken cultures, the Sc3 mRNA nevertheless accumulates at the same time as in surface cultures (Wessels et al., 1987).

The $S c 3$ gene encodes a hydrophobin, a hydrophobic cysteine-rich protein of 125 amino acids including a signal peptide for secretion. The present results show that this protein is present in the medium and the hyphal walls as a protein subunit of apparent $M_{\mathrm{r}}=28 \mathrm{~K}$. Because the deduced $M_{\mathrm{r}}$ without signal peptide is 9830 and deglycosylation lowers the apparent $M_{\mathrm{r}}$ of the excreted protein to only about $20 \mathrm{~K}$ (results not shown), it is possible that the $28 \mathrm{~K}$ protein represents a dimer of two covalently linked glycosylated chains. We calculate that at the time of synchronous formation of aerial hyphae in the mycelial lawn about $5 \%$ of all protein synthesis is directed towards synthesis of this $\mathrm{Sc} 3$ hydrophobin.

As shown, both submerged hyphae and aerial hyphae excreted the Sc3 hydrophobin. However, submerged hyphae excreted the hydrophobin into the medium and retained little in their walls, whereas aerial hyphae accumulated all hydrophobin in their walls as a hot-SDSinsoluble complex. Surface-grown mycelia prevented from forming aerial hyphae by an overlaying perforated membrane accumulated very little of this complex in their walls. Also, hyphae grown in shaken culture excreted nearly all of the hydrophobin into the culture medium (data not shown).

The complex of Sc3 hydrophobin present in the walls of aerial hyphae could be extracted with formic acid and dissociated into $28 \mathrm{~K}$ subunits by cleavage and oxidation of any cystines with performic acid. Therefore, we originally attributed complex formation to the occurrence of intermolecular disulphide bonds. We have since found that extraction and dissociation of the complex can also be achieved by treatment with trifluoroacetic acid at room temperature (data not shown), indicating the importance of hydrophobic interactions in generating the insoluble complex in the walls of aerial hyphae.

Possibly, the insolubilized Sc3 hydrophobin forms the rodlet layer seen at the hyphal wall surface of $S$. commune (Wessels et al., 1972). Such rodlets have generally been seen on the surface of spores, where they are believed to confer the hydrophobicity necessary for dispersal 
(Beever \& Dempsey, 1978); conidiospores without rodlets as found in a mutant of Neurospora crassa were easily wettable. The rodlet layer on the conidiospores of the wild-type $N$. crassa has been shown to consist of protein(s) with an amino acid composition (Beever et al., 1979) which shows similarity to that of the hydrophobins of S. commune (Schuren \& Wessels, 1990). Recently, the rodA gene from Aspergillus nidulans, implicated in the formation of conidial rodlets, was shown to code for a protein with an amino acid sequence clearly homologous to those of the S. commune hydrophobins (Stringer et al., 1991). Apparently, this class of proteins occurs both in basidiomycetes and ascomycetes.

Assuming an essential role of the Sc3 hydrophobin in the generation of the hydrophobic aerial hyphae of $S$. commune, we can envisage the following sequence of events in the development of the mycelium. After inoculation, the hyphae first grow with minimal expression of the $S c 3$ gene, but after some growth has occurred, the gene is switched on by some unknown mechanism and its mRNA accumulates (Mulder \& Wessels, 1986). The Sc3 hydrophobin is now excreted into the medium and we surmise that this potentiates the mycelium to form aerial hyphae. Hyphae emerging from the substrate would excrete the hydrophobin in their walls and thereby acquire a hydrophobic surface necessary for aerial growth. Direct evidence for this might be obtained by showing that disruption of the $S c 3$ gene prevents the emergence of aerial hyphae. Such experiments have not yet been successful because of the high incidence of the expected phenotype, due to the thn mutation, after transforming with a deleted $S c 3$ gene. Whether hydrophobic interactions between the Sc3 hydrophobin molecules are sufficient to create the insoluble hydrophobin complex in the wall of aerial hyphae, also requires further investigation. If the Sc3 hydrophobin is a determinant for aerial hyphae, the delay in expression of the $S c 3$ gene in young cultures may be important for the development of a substantial amount of submerged feeding mycelium before formation of aerial hyphae is possible. Early expression of the gene may be detrimental to development of the mycelium as a whole because aerial hyphae are unable to take up nutrients. On the other hand, failure to produce the Sc3 hydrophobin, as in the thn mutant, would lead to inability to produce aerial hyphae and could thus cause somewhat faster linear growth of submerged hyphae as observed.

\section{References}

Beever, R. E. \& Dempsey, G. P. (1978). Function of rodlets on the surface of fungal spores. Nature, London 272, 608-610.
BeEver, R. E., Redgwell, R. J. \& Dempsey, G. P. (1979). Purification and chemical characterization of the rodlet layer of Neurospora crassa conidia. Journal of Bacteriology 140, 1063-1070.

Chamberlain, J. P. (1979). Fluorographic detection of radioactivity in polyacrylamide gels with the water-soluble fluor, sodium salicylate. Analytical Biochemistry 98, 132-135.

Dons, J. J. M., DE VRIes, O. M. H. \& Wessels, J. G. H. (1979). Characterization of the genome of the basidiomycete Schizophyllum commune. Biochimica et Biophysica Acta 563, 100-112.

Hoge, J. H. C., Springer J. \& Wessels, J. G. H. (1982). Changes in complex RNA during fruit-body initiation in the fungus Schizophyllum commune. Experimental Mycology 6, 233-243.

Jovin, T. M. (1973). Multiphasic zone electrophoresis: III. Further analysis and new forms of discontinuous buffer systems. Biochemistry 12, 890-898.

LAEMMLI, U. K. (1970). Cleavage of structural proteins during the assembly of the head of bacteriophage T4. Nature, London, 227, 680685.

Moos, M., JR, NGUYEN, N. Y. \& LIU, T. Y. (1988). Reproducible high yield sequencing of proteins electrophoretically separated and transferred to an inert support. Journal of Biological Chemistry 263, 6005-6008.

Mulder, G. H. \& Wessels, J. G. H. (1986). Molecular cloning of RNAs differentially expressed in monokaryons and dikaryons of Schizophyllum commune in relation to fruiting. Experimental Myco$\log y 10,214-227$.

RAPER, C. A. (1988). Schizophyllum commune, a model for genetic studies of the Basidiomycetes. In Genetics of Plant Pathogenic Fungi, pp. 511-522. Edited by G. S. Sidhu. London: Academic Press.

RAPER, J. R. \& Miles, P. G. (1958). The genetics of Schizophyllum commune. Genetics 43, 530-546.

RuIters, M. H. J. \& Wessels, J. G. H. (1989). In situ localization of specific mRNAs in developing fruit bodies of the basidiomycete Schizophyllum commune. Experimental Mycology 13, 212-222.

Ruiters, M. H. J., Sietsma, J. H. \& Wessels, J. G. H. (1988). Expression of dikaryon-specific mRNAs of Schizophyllum commune in relation to incompatibility genes, light, and fruiting. Experimental Mycology 12, 60-69.

SCHuren, F. H. J. \& Wessels, J. G. H. (1990). Two genes specifically expressed in fruiting dikaryons of Schizophyllum commune: homologies with a gene not regulated by mating type genes. Gene 90, 199205.

Schwalb, M. N. \& Miles, P. G. (1967). Morphogenesis of Schizophyllum commune I. Morphological variation and mating behavior of the thin mutation. American Journal of Botany 54, 440446.

SPRINGER, J. \& WeSSELS, J. G. H. (1989). A frequently occurring mutation that blocks the expression of fruiting genes in Schizophyllum commune. Molecular and General Genetics 219, 486-488.

Stringer, M. A., Dean, R. A., Sewall, T. C. \& Timberlake, W. E. (1991). Rodletless, a new Aspergillus developmental mutation induced by directed gene inactivation. Genes \& Development 5 (in the Press).

De VRIES, O. M. H. \& Wessels, J. G. H. (1984). Patterns of polypeptide synthesis in non-fruiting monokaryons and a fruiting dikaryon of Schizophyllum commune. Journal of General Microbiology 130, 145154.

Wessels, J. G. H., Kreger, D. R., Marchant, R., Regensburg, B. A. \& DE VRIES, O. M. H. (1972). Chemical and morphological characterization of the hyphal wall surface of the basidiomycete Schizophyllum commune. Biochimica et Biophysica Acta 273, 346-558.

Wessels, J. G. H., Mulder, G. H. \& SPRINGER, J. (1987). Expression of dikaryon-specific and non-specific mRNAs of Schizophyllum commune in relation to environmental conditions and fruiting. Journal of General Microbiology 133, 2557-2561.

Wessels, J. G. H., de Vries, O. M. H., Äsgeirsdóttir, S. A. \& SCHUREN, F. H. J. (1991). Hydrophobin genes involved in formation of aerial hyphae and fruit bodies in Schizophyllum. The Plant Cell 3(8) (in the Press). 